\title{
Comparison of treatment outcomes between fibromyalgia and the incomplete form of fibromyalgia with the same treatment
}

\author{
Katsuhiro Toda* \\ Department of Orthopedic Surgery, Hiroshima Clinic, Japan
}

\begin{abstract}
Objective: The treatment outcomes of fibromyalgia (FM) and the incomplete form of FM (I-FM) (chronic widespread pain and chronic regional pain) in one medical institution were compared using the same FM treatment (mainly medication).

Methods: Patients with FM consisted of 31 persons ( 25 women and 6 men) and the average age was $37.4 \pm 15.9$ years old (range: 17 to 84 years old). Patients with I-FM consisted of 49 persons ( 37 women and 12 men) and the average age was $50.3 \pm 16.8$ years old (range: 16 to 86 years old). Pain was estimated in this study as follows: "If pain at the first visit is 100, what percentage is the current pain?" All patients with FM and I-FM who received medication for more than 3 months including dropout patients were included in this study. The mean treatment duration of patients with FM was $13.3 \pm 9.1$ months (range: 3 to 32 months) and that of patients with I-FM was $12.1 \pm 7.4$ months (range: 3 to 34 months).
\end{abstract}

Results: Cure was achieved in $0(0 \%)$ and $3(6.1 \%)$ patients, and pain was reduced to 30\% or less in $7(22.6 \%)$ and 21 (42.9\%), 31-50\% was 3 (9.7\%) and $8(16.3 \%)$, $51-70 \%$ was $9(29.0 \%)$ and $5(10.2 \%), 71-90 \%$ was $6(19.4 \%)$ and $4(8.2 \%)$, and $91 \%$ or more was $6(19.4 \%)$ and $8(16.3 \%)$, of FM and I-FM patients, respectively.

Discussion: Because the treatment outcome of I-FM was better than that of FM, it is desirable to provide treatment before FM actually develops.

\section{Introduction}

Fibromyalgia $(\mathrm{FM})$ is a refractory and painful disorder. The outcome of various treatment methods such as pregabalin, duloxetine, and cognitive behavioral therapy (CBT) has been reported. However, the outcome of combined total treatment of medication treatment and non-medication treatment in a single medical institution has rarely been reported. In this study, the outcome of combined total treatment of FM in a single medical institution was reported.

FM is a typical disorder of central sensitivity syndrome [1-3]. It usually takes more than a decade to develop FM from neck pain and low back pain through chronic regional pain (CRP) and chronic widespread pain (CWP) [4-13]. The diagnostic criteria of CWP and CRP are described later. CRP and CWP can be regarded as the incomplete form of FM (I-FM) or preliminary stage of FM [14]. It has been proposed that CWP is the end stage in a continuum of CRP and FM is the end stage in a continuum of CWP, rather than any of these representing distinct medical entities [14-16]. The relative severities of the clinical symptoms in each diagnosis group were reported to be $\mathrm{FM}>\mathrm{CWP}>\mathrm{CRP}$ [14]. The prevalence of FM is approximately $2 \%$ [17] and the prevalence of CWP including FM is approximately $10 \%$ $[18,19]$. The prevalence of CRP is $1-2$ times higher than that of CWP [19]. The treatment of CWP is similar to that of FM throughout the world [20]. Patients with CRP often undergo the treatment of FM. The second objective of this study is to compare the treatment outcomes of FM and I-FM in cases receiving the same treatment.

\section{Methods}

Patients with FM and I-FM (CWP and CRP) were included in this study if they first visited Hiroshima Clinic between January 2014 and October 2016. Patients who were referred from Hatsukaichi Memorial Hospital, my former place of work, to Hiroshima Clinic by myself were excluded. Eligible subjects were limited to outpatients who were physician-referred with a suspected diagnosis of FM and to those who were self-referred believing that their symptoms were due to FM. In other words, only the patients who visited the author for the purpose of receiving FM treatment were included in the study. If patients with suspected FM or IFM visited Hiroshima Clinic by chance, not for the purpose of receiving FM treatment, diagnosis of FM was not performed, and treatment centered around rehabilitation was performed. These patients were not included in the study. Subjects who met the classification criteria for FM published by the American College of Rheumatology in 1990 [21] at the first visit were diagnosed with FM. Subjects who had experienced pain in five regions described in the criteria [21] for more than three months with 10 tender points or fewer were diagnosed with CWP. Subjects without CWP whose pain was beyond chronic low back pain alone or a stiff neck alone were diagnosed with CRP. If other diseases such as hypothyroidism and rheumatoid arthritis could explain the pain, the subjects were not diagnosed with CWP and CRP. The differentiation between FM and I-FM was made based on the examination at the first visit alone.

*Correspondence to: Katsuhiro Toda, Department of Orthopedic Surgery, Hiroshima Clinic, 2-1 Takaramachi, Naka-ku, Hiroshima, 730-0044, Japan, Tel: +81-82-543-6688, Fax: +81-82-543-6689, E-mail: goutattack@yahoo.co.jp

Key words: fibromyalgia, chronic widespread pain, chronic regional pain, treatment outcomes, pharmacotherapy

Received: May 17, 2018; Accepted: July 03, 2018; Published: July 06, 2018 
This study is a retrospective study that reported the outcome of the author's routine treatment. This study was approved by the Ethics Committee of Hiroshima Clinic.

All patients with FM and I-FM who received medication for more than 3 months were included in this study. Pain of the patients was automatically examined when they had received for more than 3 months between October 18, 2016 and January 21, 2017. The pain levels were the data of this study. This method prevented intentional preferential measurements of pain when the pain was mild. The dropout patients were also included in this study by measuring pain with the method described later. Patients with comorbidities such as rheumatoid arthritis, ankylosing spondylitis, cerebrospinal fluid hypovolemia [22], anxiety disorder, and major depression were also included in this study. Patients who were not prescribed antidepressants because of bipolar disorder or patients' concerns over the adverse effects were also included in this study. Patients who received massage, rehabilitation, etc., in Hiroshima Clinic or other medical institutions were also included in this study. Patients who underwent blood patch treatment for cerebrospinal fluid hypovolemia and spinal hernia surgery during follow-up were included in this study.

The following patients were not included in this study: patients who received medication for less than 3 months; patients who underwent non-medication treatment alone such as rehabilitation for more than 3 months.

The following explanation was given to the patient at the first visit, and oral informed consent was obtained. I: Off-label medication is sometimes administered. II: Death due to the adverse effect of medication is possible. III: Patients should not take oral medication for analgesic purposes except that prescribed by Hiroshima Clinic. IV: When patients are to undergo treatment for pain relief such as acupuncture, massage, and health foods, patients have to report it in advance. V: Based on Japanese drug package inserts, operating machinery or driving motor vehicles is prohibited without exception during medication of almost all antidepressants, all anticonvulsants, and all hypnotics. However, almost all persons including police officers do not observe the rule in Japan.

"If pain at the first visit is 100 , what percentage is the current pain?" Pain was assessed with this question. All patients were asked this question every 3 or 4 months. The treatment outcome of dropout patients was estimated by repeating this question every 3 or 4 months.

Patients with FM were treated mainly with medication. Hiroshima Clinic is a primary care outpatient institution. FM is often regarded not to exist in Japan and there are few medical institutions which provide treatment for FM. Therefore, Hiroshima Clinic is also a tertiary care center for FM. A primary care outpatient institution is also a tertiary care center for FM, indicating the poor situation of FM treatment in Japan. CBT was not performed because Hiroshima Clinic does not have staff for CBT, and CBT for pain relief have to be performed for free in Japan. Aerobic exercise, weight loss, cessation of smoking, avoidance of passive smoking, cessation of aspartame and monosodium glutamate ingestion, the fewest possible administrations of medicine containing aspartame, explanation of FM, etc., were performed or recommended. Benzodiazepine anxiolytics were not administered for pain relief. Benzodiazepine anxiolytics were administered at the lowest effective dosage and for the shortest time in patients with FM (or I-FM) and concomitant panic disorder.

I prescribed medication in accordance with the recommendations of pharmacologic management of neuropathic pain published by the
International Association for the Study of Pain [23]. Slow titration from a low initial dosage was performed for one medicine alone and the maximum dosage of medication was administered unless the adverse effects limited the upward titration, or a medication provided adequate pain relief [23]. If a medication was well-tolerated and provided partial pain relief, it was continued and a second medication with a different action mechanism was added [23]. If the initial dosage was the maximum dosage and 4-week medication was not effective, the medicine was discontinued. Specifically, individual medicine corresponded to one of the following options (Figure 1). I: The medication provided adequate pain relief. II: The medication did not provide pain relief and it caused intolerable adverse effects. III: The maximum dosage of medication did not provide pain relief. IV: The maximum dosage of medication provided partial pain relief. V: The medication provided partial pain relief; however, the adverse effects limited upward titration. The maximum dosage was used unless a medication provided adequate pain relief or the adverse effects limited upward titration. A medicine was not regarded as ineffective unless the maximum dosage was administered. In the case of I, the same medication was continued. In cases of II and III, the next medicine was added in a similar manner after (or during) the dosage was gradually decreased and discontinued. In cases of IV and V, the next medicine was added in a similar manner after patients compared the analgesic effect with the adverse effects to determine the optimum dosage. The presence or absence of the analgesic effect of an individual medicine was determined according to figure 1. If a medicine was effective, the analgesic and adverse effects were compared to determine the optimum dosage. Determination of the optimum dosage was carefully performed. If the analgesic effect was unclear, gradual increases and decreases were sometimes repeated. If the maximum dosage of medication provided unclear pain relief, the medication was always discontinued and any changes in pain were examined. Patients made the decision regarding the differentiation between adequate and partial pain relief; in other words, patients decided whether or not to try the next medicine.

I have categorized 12 kinds of medicines according to the literaturebased efficacy and adverse effects, personal experience of the efficacy and adverse effects, drug price, severity of off-label medication, and medicine whose use prohibits driving motor vehicles. Specifically, my order of priority is Neurotropin ${ }^{\circledR}$ (an extract from the inflamed skin of vaccinia virus-inoculated rabbits), amitriptyline, dextromethorphan, nortriptyline, mecobalamin (Vitamin B12) plus folic acid, ethyl icosapentate, lafutidine, milnacipran, gabapentin, duloxetine, pregabalin, and venlafaxine, in that order (Table 1). Medication was usually performed in that order.

The treatment outcome was classified into cure, reduction to $30 \%$ or less, $31-50 \%, 51-70 \%, 71-90 \%$, and $91 \%$ or more. Cure was defined as follows: Pain decreased to $30 \%$ or less of that on the first visit and pain was not exacerbated even if medication excluding hypnotics was discontinued for more than 3 months. Cure was confirmed by face-toface or telephone interview. In the case of patients being referred to other medical institutions, pain at referral was the treatment outcome. In the case of pain decreasing to $30 \%$ or less of that on the first visit without confirmation of the discontinuation of medication for more than 3 months, the treatment outcome was not cure but $30 \%$ or less.

Patients with FM consisted of 31 persons ( 25 women and 6 men), and the average age was $37.4 \pm 15.9$ years old (range: 17 to 84 years old). Patients with I-FM consisted of 49 persons (37 women and 12 men), and the average age was $50.3 \pm 16.8$ years old (range: 16 to 86 years old). 
Table 1. Priority of medicine for neuropathic pain (fibromyalgia).

\begin{tabular}{|c|c|c|c|c|c|c|c|c|c|}
\hline & Medicine & ఫ్ర & $\begin{array}{l}\text { Off-label } \\
\text { use }\end{array}$ & Disease name & 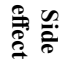 & $\begin{array}{l}\text { 중 } \\
\stackrel{7}{\rightleftarrows}\end{array}$ & 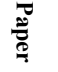 & Upper limit & Price at upper limit (yen) in March 2018. \\
\hline 1 & Neurotropin $^{\circledR}$ & () & () & lumbago, osteoarthritis & (0) & (0) & IV & 4 tab. & 124.4 \\
\hline 2 & amitriptyline & $\times$ & () & peripheral NP & $\triangle$ & (-) & I & $150 \mathrm{mg}$ & $25 \mathrm{mg} \mathrm{57.6/10} \mathrm{mg} 144$ \\
\hline 3 & dextromethorphan & $\times$ & $\times$ & chronic brochitis & (-) & (-) & IIa & $120 \mathrm{mg}$ & 44.8 \\
\hline 4 & nortriptyline & $x$ & $\circ$ & depression & $\triangle$ & (0) & $\mathrm{C}$ & $150 \mathrm{mg}$ & $25 \mathrm{mg} \mathrm{64.8/10} \mathrm{mg} 84$ \\
\hline \multirow{2}{*}{5} & vitamin B12 & (-) & ( ) & peripheral neuropathy & \multirow{2}{*}{ () } & \multirow{2}{*}{$\circ$} & \multirow{2}{*}{$\mathrm{IV}^{*}$} & $1500 \mu \mathrm{g}$ & $51.3 /{ }^{\#} 16.8$ \\
\hline & folic acid & (○) & $\times$ & folate deficiency & & & & $20 \mathrm{mg}$ & 38.4 (usually15mg 28.8) \\
\hline 6 & ethyl icosapentate & () & $\times$ & hyperlipidemia & (0) & $\triangle$ & IV & $1800 \mathrm{mg}$ & $210.8 /{ }^{\#} 88$ \\
\hline 7 & lafutidine & () & $\triangle$ & gastric ulcer & (-) & $\triangle$ & $\mathrm{IV}^{*}$ & $20 \mathrm{mg}$ & $70.2 /{ }^{\#} 40.6$ \\
\hline 8 & milnacipran & $\circ$ & $\circ$ & depression & $\triangle$ & (0) & I & $100 \mathrm{mg}$ & $50 \mathrm{mg} \mathrm{101.6/50} \mathrm{mg} \mathrm{\# 62.6}$ \\
\hline 9 & gabapentin & $x$ & $x$ & seizure & $\triangle$ & (0) & IIa & $2400 \mathrm{mg}$ & $400 \mathrm{mg} 397.8 / 200 \mathrm{mg} 484.8$ \\
\hline 10 & duloxetine & $\circ$ & ( ) & FM, chronic lumbago & $\triangle$ & (-) & $\mathrm{I}$ & $60 \mathrm{mg}$ & $30 \mathrm{mg} 470.6 / 20 \mathrm{mg} 520.5$ \\
\hline \multirow{2}{*}{11} & \multirow{2}{*}{ pregabalin } & \multirow{2}{*}{$\times$} & () & FM (fibromyalgia) & \multirow{2}{*}{$\triangle$} & \multirow{2}{*}{ ○ } & \multirow{2}{*}{ I } & $450 \mathrm{mg}$ & $150 \mathrm{mg} 465 / 75 \mathrm{mg} 677.4$ \\
\hline & & & ( ) & NP (neuropathic pain) & & & & $600 \mathrm{mg}$ & $150 \mathrm{mg} \mathrm{620/75} \mathrm{mg} 903.2$ \\
\hline 12 & venlafaxine & $\circ$ & $\circ$ & depression & $\triangle$ & () & I\# & $225 \mathrm{mg}$ & 797.7 \\
\hline
\end{tabular}

I systematic review, meta-analysis,I\#systematic review,IIa randomized double-blind study

IV open-label study, C case study, *abstract \#generic Side effect and effect are based on my experience

Description of driving ban in package inserts of pregabalin is strict.

Neurotropin ${ }^{\circledR}$ (used in Japan and China) is under randomized, double-blind study for FM in NIH of USA.

Drive (in Japan) $\bigcirc$ : possible, $\circ$ : conditionally possible, $\times$ : impossible

Off-label use in Japan @: no problem, ○: perhaps no problem, $\triangle$ : problematic, $\times$ : extremely problematic

Side effect (based on both the literature and my experience on actual use) $\bigcirc:$ mild, $\triangle:$ moderate

Effect (based on my experience) ๑: strong, $\circ$ : moderate, $\triangle$ : mild

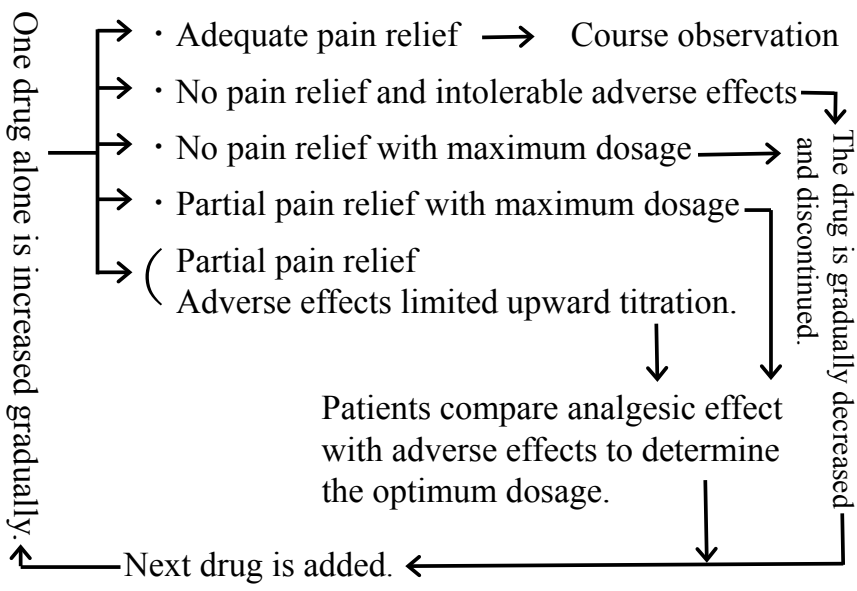

Figure 1. Medication method of individual medicine

\section{Statistical analyses}

The ratio of the total number of patients whose pain was decreased to $30 \%$ or less, $50 \%$ or less, $70 \%$ or less, and $90 \%$ or less between FM and I-FM patients was compared using the chi-squared test. The ratio of the number of cured patients between FM and I-FM patients was compared using Fisher's exact test, because at least one variable was 5 or less. $p<0.05$ was considered significant.

\section{Results}

The mean treatment duration of patients with FM was $13.3 \pm 9.1$ months (range: 3 to 32 months) and that of patients with I-FM was 12.1 \pm 7.4 months (range: 3 to 34 months). Cure was achieved in $0(0 \%)$ and $3(6.1 \%)$ patients, and pain was reduced to $30 \%$ or less in $7(22.6 \%)$ and 21 (42.9\%), $31-50 \%$ was 3 (9.7\%) and 8 (16.3\%), $51-70 \%$ was $9(29.0 \%)$ and $5(10.2 \%), 71-90 \%$ was $6(19.4 \%)$ and $4(8.2 \%)$, and $91 \%$ or more was $6(19.4 \%)$ and 8 (16.3\%), of FM and I-FM patients, respectively (Figure 2).

\section{Statistical analyses}

The number of cured patients in FM and I-FM patients was 0 (0\%) and $3(6.1 \%)$ patients $(p=0.4236)$, respectively. The total number of patients whose pain was decreased to $30 \%$ or less in FM and I-FM patients was $7(22.6 \%)$ and $24(49.0 \%)(p=0.0182), 50 \%$ or less was 10 $(32.2 \%)$ and $32(65.3 \%)(p=0.0036), 70 \%$ or less was $19(61.3 \%)$ and 37 $(75.5 \%)(p=0.1763)$, and $90 \%$ or less was $25(80.6 \%)$ and $41(83.7 \%)(p$ $=0.7284)$, respectively.

\section{Discussion}

The outcome of various treatment methods such as pregabalin, duloxetine, and CBT has been reported. However, the outcomes of all combined treatments of medication and non-medication treatments in one medical institution have rarely been reported. The study of Kim et al. [24] reported the outcomes of combined treatments (medication and non-medication treatments) of 48 patients with FM in 2 medical institutions; however, the outcomes of 84 dropout patients with FM were not included [24]. To my knowledge, this is the first study to report the outcome of combined treatments of FM and I-FM including dropout patients in a single medical institution.

The medication guidelines for neuropathic pain [23] and FM [25] were mainly based on scientific evidence of efficacy in the literature. From the viewpoint of science, it is justified, however, it does not necessarily agree with clinical priority [26]. (1) Many pharmaceutical companies provide huge amounts of financial assistance to studies that show the efficacy of expensive medicine that hugely benefits the companies. Consequently, reports of such medicines are frequently published, which strengthens scientific evidence. Conversely, scientific evidence of inexpensive medicine does not increase. In my experience, nortriptyline is effective for FM; however, limited scientific evidence shows its efficacy. I believe that the low drug price is the main cause. Fabricated study is beside the question. No association of industry funding or the authors' financial conflicts of interest with the study 


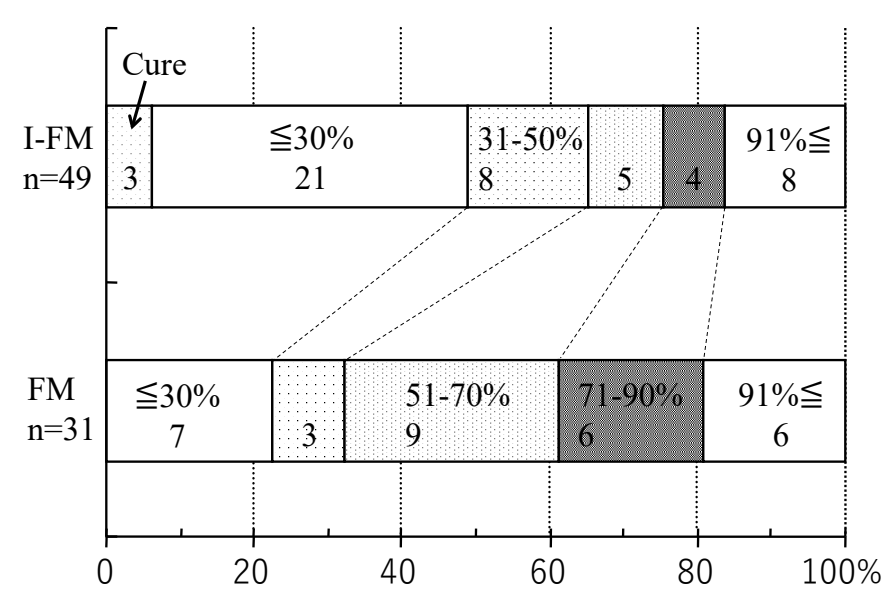

Figure 2. Treatment of outcomes of fibromyalgia (FM) and incomplete form of FM (I-FM).

I-FM is chronic widespread pain and chronic regional pain. Pain was estimated in this study as follows: "If pain at the first visit is 100, what percentage is the current pain?" All patients with FM and I-FM who received medication for more than 3 months including dropout patients were included in this study. Cure was defined as follows: Pain decreased to $30 \%$ or less of that on the first visit and pain was not exacerbated even if medication excluding hypnotics was discontinued for more than 3 months. Cure was confirmed by face-to-face or telephone interview. In the case of pain decreasing to $30 \%$ or less of that on the first visit without confirmation of the discontinuation of medication for more than 3 months, the treatment outcome was not cure but $30 \%$ or less.

outcomes was seen in FM drug therapy randomized controlled trials [27]. However, many reports including systematic reviews show that pharmaceutical company sponsorship is strongly associated with results that favor the sponsors' interests [28-33]. (2) In clinical practice, drug price, adverse effects, and degree of off-label use in addition to scientific evidence of efficacy should be reflected in the order of priority. Adverse effects slightly affect these guidelines. Most adverse effects that were considered in the development of guidelines for neuropathic pain and FM were short-term adverse effects such as nausea, vomiting, diarrhea, drowsiness, constipation, dysuria, and dry mouth. These adverse effects have a clear causal relationship and are easy to identify. They disappear as soon as the causative drug is discontinued. However, the adverse effects that should be considered in medication are the long-term adverse effects such as cognitive dysfunction, dependence or abuse, sexual dysfunction, osteoporosis, and fracture. These adverse effects have an unclear causal relationship and are difficult to identify. Improvement of these long-term adverse effects is impossible or difficult after the causative drug is discontinued. These long-term adverse effects cannot be applied to "the analgesic effect and the adverse effects were compared to determine the optimum dosage." They are usually not reflected in the medication guidelines for neuropathic pain and FM. However, they were reflected in my medication order of priority. For example, pregabalin is an excellent medicine with a strong analgesic effect based on both the literature and my experience on actual use. However, the adverse effects of pregabalin are cognitive dysfunction [34,35], dependence or abuse [36-40], obesity [41], marked drowsiness (sometimes loss of consciousness), and an expensive drug price. Therefore, my order of priority places it at the 11th. Two short-term studies reported cognitive dysfunction $[34,35]$ due to pregabalin. Cognitive dysfunction may continue for a long time. It is almost impossible to detect long-lasting cognitive dysfunction at the individual patient level. It is unknown whether long-lasting cognitive dysfunction improves after the discontinuation of medication. In my experience, sleepiness caused by antidepressants occurs gradually, and sleepiness caused by pregabalin sometimes occurs suddenly (loss of consciousness). Loss of consciousness caused by pregabalin is described in drug package inserts. From the viewpoint of traffic accidents and falls, loss of consciousness is far more dangerous than gradual sleepiness. The adverse effects of duloxetine are cognitive dysfunction [42-44], sexual dysfunction [45], and bleeding [46] and the drug price is expensive; therefore, its order of priority is the 10th. Long-term studies $[47,48]$ and a systematic review and meta-analysis [43] showed that SNRI increased the risk of dementia. Amitriptyline is said to be difficult to use because it has frequent adverse effects. Most adverse effects except obesity occur early in medication and are easy to identify. The price of amitriptyline is inexpensive and most adverse effects except obesity disappear as soon as it is discontinued. Obesity is an adverse effect and it does not disappear immediately after the discontinuation of medication. However, it is easy to identify obesity if the body weight is measured. A large German cohort showed that amitriptyline was associated with patients with severe cognitive impairment [49], a population-based case-control study showed that TCA had no association with the dementia risk [48], and a populationbased, retrospective case-control study showed that TCA reduced the risk of dementia [42]. A systematic review and meta-analysis showed that TCA may be associated with a reduced risk or no risk of dementia, and serotonin noradrenaline reuptake inhibitors (SNRIs) have been reported to show an intermediate risk [43]. Therefore, TCA is safer than SNRIs in terms of dementia or cognitive dysfunction [42-44,48,50]. In fact, amitriptyline is an easy-to-use medicine and it is safe for patients; therefore, its order of priority is the second. All patients who would like to receive medication underwent an electrocardiogram. If the electrocardiogram showed an abnormality, the patients were referred to a cardiologist to confirm whether amitriptyline could be administered. A meta-analysis of observational studies in subjects with no history of coronary heart disease suggests that neither selective serotonin reuptake inhibitor nor TCA use is associated with an increased risk of coronary heart disease [51]. A retrospective cohort study reported that current users of TCA had a dose-related increase in the risk of sudden cardiac death and the rate ratios was 0.97 ( $95 \%$ confidence interval, 0.72-1.29) for doses lower than $100 \mathrm{mg}$ (amitriptyline or its equivalent) [52]. Therefore, if the cardiotoxicity of amitriptyline was a concern due to an advanced age, etc., the maximum dosage was decreased from 150 to $95 \mathrm{mg}$. Neurotropin is administered only in Japan and China, and some case reports and open studies showed its efficacy for FM [53]. It does not cause drowsiness and is a very safe drug with few adverse effects. In my experience, the analgesic effect of Neurotropin ${ }^{\star}$ is similar to that of amitriptyline [54]. A double-blind, randomized controlled study of Neurotropin ${ }^{\star}$ in patients with FM was performed in the US National Institutes of Health (ClinicalTrials. gov Identifier: NCT00366535). Although the maximum dosage of Neurotropin ${ }^{\circledast}$ is four tablets, eight tablets were more effective than four tablets with the adverse effects showing little difference in general terms [53]. Therefore, when possible such as after traffic accidents, eight tablets were administered. TCA is safer than SNRIs in terms of dementia or cognitive dysfunction [42-44,48,50]. It is one reason why I prioritized TCA over SNRI. The drug price strongly influenced the order of priority after milnacipran. The scientific basis of lafutidine and combination of mecobalamin (Vitamin B12) and folic acid in FM is mainly reported in the Japanese literature. The Japanese College of Fibromyalgia Investigation classified FM into the hypertonus type, enthesitis type, depression type, and their combination [55]. It recommended specific pharmacological treatment for each type of FM. For example, predonine, salazosulfapyridine, etc., were recommended for the enthesitis type of FM. The algorithm of pharmacotherapy [55] published by the Japanese College of Fibromyalgia Investigation is not 
based on evidence and it causes confusion in the treatment of FM. Therefore, I did not use it.

I usually administered medication based on the order of priority; however, it is true that there are exceptions. If having fewer adverse effects took top priority, amitriptyline and nortriptyline were administered after lafutidine. If pain was severe, amitriptyline, SNRIs, gabapentin, and pregabalin were preferentially administered. Because this list includes my subjective view, the absence of clear evidence is a shortcoming. Available medicine, applicable diseases, and drug price differ from country to country. Priority depends on the physician. Therefore, the order of priority of medication depends on the country and physician. Medication based on a list of the order of priority is easy. Non-specialists can easily treat FM using the list of each physician. The distinction between a uniform medication order based on the list and exceptional medication order is important. Naturally, it is impossible to treat all patients successfully with these 12 medications alone. Antidepressants and anticonvulsants not included in the list, tizanidine, gabapentin enacarbil, herbal medicine, weak opioids, and rarely strong opioids, etc., were also administered. Ineffective medicines were sometimes administered again in combination.

I am absolutely confident in the treatment outcomes of FM and I-FM. This does not mean that the treatment outcomes are excellent. I am confident that I made strict judgments. Patients with poor outcomes were not excluded and dropout patients were included in this study. Because a face-to-face interview was conducted, I do not deny the possibility that patients may have reported a good treatment outcome in consideration of the physician (me). Because the treatment outcomes of FM and I-FM were measured using the same method, there is no problem with comparison between them. Because the treatment outcomes of FM in other medical institutions were not reported, nobody knows how wonderful my treatment outcomes are.

In this study, I limited the treatment period to more than 3 months. If the cut-off period is 2 months, patients receiving only a few medicines will be included. If the cut-off period is 6 months, many patients who drop out of treatment because of dissatisfaction with the treatment outcome will be excluded. Although there is no clear evidence, I believe that a 3-month cut-off period is appropriate. The treatment outcomes of patients who were treated for several months were naturally included in this study. It takes approximately a year and a half to use all medicines in the list. Therefore, it is estimated that the actual treatment outcome (the treatment outcome at least with all medicines in the list) is better than that of this study.

The dropout patients who received medication for more than 3 months were included in this study. Some patients stop visiting the hospital based on their own judgement because of improvement of pain, and some patients would like to be referred to nearby medical institutions because of improvement. However, dropout patients usually stop visiting the hospital based on their own judgement because adverse effects occur, or pain is not improved. A treatment outcome excluding dropout patients is not a true treatment outcome.

Pain was estimated in this study as follows: "If pain at the first visit is 100 , what percentage is the current pain?" Pain of all patients must be measured every 3 or 4 months in clinical practice to include dropout patients. Therefore, a pain evaluation method whose measurement time is short is necessary. The measurement time for visual analog scale and face scale is short; however, when pain and the quality of life improved (or deteriorated) they often conversely deteriorated (or improved) in my experience. Also, in my experience, the measurement method used in this study correlates well with the change of pain and the quality of life. The measurement method used in this study was the most reliable evaluation method for determining the analgesic effect of individual medicines in my clinical practice. I hope that the comprehensive treatment outcome of FM including dropout patients in each medical institution will be reported with this evaluation method.

Treatment for CWP is similar to that for FM throughout the world [20]. I have treated FM and I-FM with the same treatment method. In addition, I have generally treated non-nociceptive pain or neuropathic pain (excluding trigeminal neuralgia, the early stage of complex regional pain syndrome, the attack stage of cluster headache and migraine, etc.) using a treatment for FM. In non-nociceptive pain, my treatments of patients with FM and without FM are generally identical. The diagnostic criteria of FM are useful for diagnosis; however, they are not useful for treatment [56]. To put it briefly, I believe that the significance of the criteria is to identify uniform patients with FM in medical journals and/or medical meetings. This is the same situation as for obesity. If the definition of obesity is a body mass index (BMI) of 30 or higher, the treatment for patients with a BMI of 29.9 and 30 should be the same. However, patients with a BMI of 29.9 are excluded from medical journals and/or medical meetings on obesity. Whatever diagnostic criteria of FM are reported, this situation will not change. Because the treatment outcome of I-FM was better than that of FM, it is desirable to perform treatment of FM in the condition before FM. I think that the principle of early detection and early treatment in medicine can also be applied to FM.

The criteria for the discontinuation of medication in cases of a successful response have not been clearly defined. I personally devised the following discontinuation criteria based on my experience: Pain is less than $30 \%$ of that on the first visit for more than 10 months and there is little fluctuation of pain due to changes in the weather conditions and menstrual cycle. Some patients who stopped going to the hospital for approximately 6 months because of improvement of pain may have no recurrence of pain. Conversely, some patients who met my discontinuation criteria had recurrence of pain. Even discontinuation criteria based on personal experience are essential in clinical practice, for example, for explanation to patients. I hope that scientific organizations will report discontinuation criteria in the presence of excellent responses.

Based on Japanese drug package inserts, driving motor vehicles is prohibited without exception during medication of almost all antidepressants except 6 antidepressants (milnacipran, duloxetine, venlafaxine, sertraline, paroxetine, and escitalopram), all anticonvulsants, all anxiolytic, all hypnotics, all antipsychotics, and all mood-stabilizing drugs. In case of a trial, a violation of the drug package inserts is equivalent to a violation of the law. If this rule is observed, many persons will lose their jobs, many persons' lives will be adversely affected, and the Japanese economy will collapse. Even police officers do not observe the rule; however, physicians must explain it to the patients. I have explained it to patients, but I do not know whether the rule was observed. I hope that the Japanese drug package inserts will be changed to the US-style statement that "patients should be cautioned about operating machinery or driving motor vehicles until they are reasonably certain the "drug name" treatment does not affect their ability to engage in such activities".

\section{Limitations}

First, this was a retrospective study with a small number of patients. Second, the visual analog scale and/or fibromyalgia impact questionnaire was not used in this study. Third, because I conducted 
a face-to-face interview, I cannot deny the possibility that patients reported a better treatment outcome with consideration for the physician.

\section{Conclusions}

If medication was administered for more than 3 months, cure was achieved in $0(0 \%)$ and $3(6.1 \%)$ patients, and pain was reduced to $30 \%$ or less in $7(22.6 \%)$ and $21(42.9 \%), 31-50 \%$ was $3(9.7 \%)$ and 8 (16.3\%), $51-70 \%$ was 9 (29.0\%) and $5(10.2 \%), 71-90 \%$ was $6(19.4 \%)$ and $4(8.2 \%)$, and $91 \%$ or more was $6(19.4 \%)$ and $8(16.3 \%)$, of 31 FM patients and 49 I-FM patients including the dropout patients, respectively. Because the treatment outcome of I-FM was better than that of FM, it is desirable to perform treatment of FM in the condition before FM.

\section{Conflict of interest}

The author has no conflicts of interest to declare.

\section{Acknowledgements}

I thank Medical English Service for reviewing this manuscript.

\section{References}

1. Yunus MB (2007) Fibromyalgia and overlapping disorders: the unifying concept of central sensitivity syndromes. Semin Arthritis Rheum 36: 339-356. [Crossref]

2. Yunus MB (2012) The prevalence of fibromyalgia in other chronic pain conditions. Pain Res Treat 2012: 584573. [Crossref]

3. Boomershine CS (2015) Fibromyalgia: the prototypical central sensitivity syndrome. Curr Rheumatol Rev 11: 131-145. [Crossref]

4. Lapossy E, Maleitzke R, Hrycaj P, Mennet W, Muller W (1995) The frequency of transition of chronic low back pain to fibromyalgia. Scand J Rheumatol 24: 29-33. [Crossref]

5. Forseth KO, Forre O, Gran JT (1999) A 5.5 year prospective study of self-reported musculoskeletal pain and of fibromyalgia in a female population: significance and natural history. Clin Rheumatol 18: 114-121. [Crossref]

6. Bergman S, Herrstrom P, Jacobsson LT, Petersson IF (2002) Chronic widespread pain: a three year followup of pain distribution and risk factors. J Rheumatol 29: 818-825. [Crossref]

7. Nicholl BI, Macfarlane GJ, Davies KA, Morriss R, Dickens C, et al. (2009) Premorbid psychosocial factors are associated with poor health-related quality of life in subjects with new onset of chronic widespread pain - results from the EPIFUND study. Pain 141: 119-126. [Crossref]

8. Gupta A, Silman AJ, Ray D, Morriss R, Dickens C, et al. (2007) The role of psychosocia factors in predicting the onset of chronic widespread pain: results from a prospective population-based study. Rheumatology (Oxford) 46: 666-671. [Crossref]

9. McBeth J, Silman AJ, Gupta A, Chiu YH, Ray D, et al. (2007) Moderation of psychosocial risk factors through dysfunction of the hypothalamic-pituitary-adrenal stress axis in the onset of chronic widespread musculoskeletal pain: findings of a population-based prospective cohort study. Arthritis Rheum 56: 360-371. [Crossref]

10. Mourao AF, Blyth FM, Branco JC (2010) Generalised musculoskeletal pain syndromes. Best Pract Res Clin Rheumatol 24: 829-840. [Crossref]

11. Forseth KO, Gran JT, Husby G (1997) A population study of the incidence of fibromyalgia among women aged 26-55 yr. Br J Rheumatol 36: 1318-1323. [Crossref]

12. McBeth J, Lacey RJ, Wilkie R (2014) Predictors of New-Onset Widespread Pain in Older Adults: Results from a Population-Based Prospective Cohort Study in the UK. Arthritis Rheumatol 66: 757-767. [Crossref]

13. Kindler LL, Jones KD, Perrin N, Bennett RM (2010) Risk factors predicting the development of widespread pain from chronic back or neck pain. J Pain 11: 13201328. [Crossref]

14. Toda K (2011) Comparison of symptoms among fibromyalgia syndrome, chronic widespread pain, and an incomplete form of chronic widespread pain. J Musculoskelet Pain 19: 52-55.
15. Staud R (2009) Chronic widespread pain and fibromyalgia: two sides of the same coin? Curr Rheumatol Rep 11: 433-436. [Crossref]

16. Hauser W, Eich W, Herrmann M, Nutzinger DO, Schiltenwolf M, et al. (2009) Fibromyalgia syndrome: classification, diagnosis, and treatment. Dtsch Arztebl Int 106: 383-391. [Crossref]

17. Toda K (2007) The prevalence of fibromyalgia in Japanese workers. Scand J Rheumatol 36: 140-144. [Crossref]

18. Mansfield KE, Sim J, Jordan JL, Jordan KP (2016) A systematic review and metaanalysis of the prevalence of chronic widespread pain in the general population. Pain 157: 55-64. [Crossref]

19. Toda K, Harada T (2010) Prevalence, classification, and etiology of pain in Parkinson's disease: association between Parkinson's disease and fibromyalgia or chronic widespread pain. Tohoku J Exp Med 222: 1-5. [Crossref]

20. Toda K (2010) Treatment of chronic widespread pain is similar to treatment of fibromyalgia throughout the world. J Musculoskelet Pain 18: 317-318.

21. Wolfe F, Smythe HA, Yunus MB, Bennett RM, Bombardier C, et al. (1990) The American College of Rheumatology 1990 Criteria for the Classification of Fibromyalgia. Report of the Multicenter Criteria Committee. Arthritis Rheum 33: 160-172. [Crossref]

22. Toda K, Moriyama E, Ishikawa S (2008) A fibromyalgia patient with traumatic cerebrospinal fluid leak: a case report. Clin Rheumatol 27: 1203-1204. [Crossref]

23. Dworkin RH, O'Connor AB, Backonja M, Farrar JT, Finnerup NB, et al. (2007) Pharmacologic management of neuropathic pain: evidence-based recommendations. Pain 132: 237-251. [Crossref]

24. Kim JE, Park DJ, Choi SE, Kang JH, Yim YR, et al. (2016) Predictors of a favourable outcome in patients with fibromyalgia: results of 1-year follow-up. Clin Exp Rheumatol 34: 521-526. [Crossref]

25. Thieme K, Mathys M, Turk DC (2017) Evidenced-Based Guidelines on the Treatmen of Fibromyalgia Patients- Are They Consistent and If Not, Why Not? Have effective psychological treatments been overlooked? J Pain 18: 747-756. [Crossref]

26. Toda K (2018) The Medication Guidelines for Neuropathic Pain Including Fibromyalgia is justified from a Scientific Viewpoint, However, it does Not Necessarily Agree with Clinical Priority. Fibromyalgia: Open Access 3: 1000128.

27. Pang WK, Yeter KC, Torralba KD, Spencer HJ, Khan NA (2015) Financial conflicts of interest and their association with outcome and quality of fibromyalgia drug therapy randomized controlled trials. Int J Rheum Dis 18: 606-615. [Crossref]

28. Bekelman JE, Li Y, Gross CP (2003) Scope and impact of financial conflicts of interest in biomedical research: a systematic review. JAMA 289: 454-465. [Crossref]

29. Sismondo S (2008) Pharmaceutical company funding and its consequences: a qualitative systematic review. Contemp Clin Trials 29: 109-113. [Crossref]

30. Cosgrove L, Shi L, Creasey DE, Anaya-McKivergan M, Myers JA, et al. (2011) Antidepressants and Breast and Ovarian Cancer Risk: A Review of the Literature and Researchers' Financial Associations with Industry. PLoS One 6: e18210. [Crossref]

31. Sinyor M, Schaffer A, Smart KA, Levitt AJ, Lanctot KL, Grysman NH (2012) Sponsorship, antidepressant dose, and outcome in major depressive disorder: metaanalysis of randomized controlled trials. $J$ Clin Psychiatry 73: e277-287. [Crossref]

32. Becker JE, Krumholz HM, Ben-Josef G, Ross JS (2014) Reporting of results in ClinicalTrials.gov and high-impact journals. JAMA 311: 1063-1065. [Crossref]

33. Ebrahim S, Bance S, Athale A, Malachowski C, Ioannidis JP (2016) Meta-analyses with industry involvement are massively published and report no caveats for antidepressants. J Clin Epidemiol 70: 155-163. [Crossref]

34. Salinsky M, Storzbach D, Munoz S (2010) Cognitive effects of pregabalin in healthy volunteers: A double-blind, placebo-controlled trial. Neurology 74: 755-761. [Crossref]

35. Sanderson C, Quinn SJ, Agar M, Chye R, Clark K, et al. (2016) Pharmacovigilance in hospice/palliative care: net effect of pregabalin for neuropathic pain. BMJ Support Palliat Care 6: 323-330. [Crossref]

36. Schjerning O, Rosenzweig M, Pottegard A, Damkier P, Nielsen J (2016) Abuse Potential of Pregabalin: A Systematic Review. CNS Drugs 30: 9-25. [Crossref]

37. Chiappini S, Schifano F (2016) A Decade of Gabapentinoid Misuse: An Analysis of the European Medicines Agency's 'Suspected Adverse Drug Reactions' Database. CNS Drugs 30: 647-654. [Crossref]

38. Evoy KE, Morrison MD, Saklad SR (2017) Abuse and Misuse of Pregabalin and Gabapentin. Drugs 77: 403-426. [Crossref] 
39. Bossard JB, Ponte C, Dupouy J, Lapeyre-Mestre M, Jouanjus E (2016) Disproportionality Analysis for the Assessment of Abuse and Dependence Potential of Pregabalin in the French Pharmacovigilance Database. Clin Drug Investig 36: 735742. [Crossref]

40. Driot D, Chicoulaa B, Jouanjus E, Dupouy J, Oustric S, et al. (2016) Pregabalin use disorder and secondary nicotine dependence in a woman with no substance abuse history. Therapie 71: 575-578. [Crossref]

41. Cabrera J, Emir B, Dills D, Murphy TK, Whalen E, et al. (2012) Characterizing and understanding body weight patterns in patients treated with pregabalin. Curr Med Res Opin 28: 1027-1037. [Crossref]

42. Lee CW, Lin CL, Sung FC, Liang JA, Kao CH (2016) Antidepressant treatment and risk of dementia: a population-based, retrospective case-control study. J Clin Psychiatry 77: 117-122. [Crossref]

43. Moraros J, Nwankwo C, Patten SB, Mousseau DD (2017) The association of antidepressant drug usage with cognitive impairment or dementia, including Alzheimer disease: A systematic review and meta-analysis. Depress Anxiety 34: 217-226. [Crossref]

44. Then CK, Chi NF, Chung KH, Kuo L, Liu KH, et al. (2017) Risk analysis of use of different classes of antidepressants on subsequent dementia: A nationwide cohort study in Taiwan. PLoS One 12: e0175187. [Crossref]

45. Duenas H, Lee A, Brnabic AJ, Chung KF, Lai CH, et al. (2011) Frequency of treatmentemergent sexual dysfunction and treatment effectiveness during SSRI or duloxetine therapy: 8-week data from a 6-month observational study. Int J Psychiatry Clin Pract 15: 80-90. [Crossref]

46. Perahia DG, Bangs ME, Zhang Q, Cheng Y, Ahl J, et al. (2013) The risk of bleeding with duloxetine treatment in patients who use nonsteroidal anti-inflammatory drugs (NSAIDs): analysis of placebo-controlled trials and post-marketing adverse event reports. Drug Healthc Patient Saf 5: 211-219. [Crossref]
47. Bali V, Holmes HM, Johnson ML, Chen H, Fleming ML, et al. (2016) Comparative Effectiveness of Second-Generation Antidepressants in Reducing the Risk of Dementia in Elderly Nursing Home Residents with Depression. Pharmacotherapy 36: 38-48. [Crossref]

48. Lee CW, Lin CL, Lin PY, Thielke S, Su KP, et al. (2017) Antidepressants and risk of dementia in migraine patients: A population-based case-control study. Prog Neuropsychopharmacol Biol Psychiatry 77: 83-89. [Crossref]

49. Pfistermeister B, Tumena T, Gassmann KG, Maas R, Fromm MF (2017) Anticholinergic burden and cognitive function in a large German cohort of hospitalized geriatric patients. PLoS One 12: e171353. [Crossref]

50. Kessing LV, Sondergard L, Forman JL, Andersen PK (2009) Antidepressants and dementia. J Affect Disord 117: 24-29. [Crossref]

51. Oh SW, Kim J, Myung SK, Hwang SS, Yoon DH (2014) Antidepressant use and risk of coronary heart disease: meta-analysis of observational studies. Br J Clin Pharmacol 78: 727-737. [Crossref]

52. Ray WA, Meredith S, Thapa PB, Hall K, Murray KT (2004) Cyclic antidepressants and the risk of sudden cardiac death. Clin Pharmacol Ther 75: 234-241. [Crossref]

53. Toda K, Tobimatsu Y (2008) Efficacy of neurotropin in fibromyalgia: a case report. Pain Med 9: 460-463. [Crossref]

54. Toda K (2008) Comparison of efficacy between neurotropin and amitriptyline in fibromyalgia. Abstracts of the12th World Congress on Pain. International Association for the Study of Pain. Glasgow; PT181.

55. Japanese College of Fibromyalgia Investigation. Fibromyalgia Practical Guideline 2013. Tokyo: Nihon-Iji-Shinpousha 2013 (In Japanese)

56. On AY, Aykanat D, Atamaz FC, Eyigor C, Kocanogullari H, et al. (2015) Is it necessary to strictly diagnose fibromyalgia syndrome in patients with chronic widespread pain? Clin Rheumatol 34: 1473-1479. [Crossref]

Copyright: (C2018 Toda K. This is an open-access article distributed under the terms of the Creative Commons Attribution License, which permits unrestricted use, distribution, and reproduction in any medium, provided the original author and source are credited. 